\title{
Visual orientation by the crown-of-thorns starfish (Acanthaster planci)
}

\author{
Ronald Petie $^{1} \cdot$ Michael R. Hall $^{2} \cdot$ Mia Hyldahl $^{1} \cdot$ Anders Garm $^{1}$
}

Received: 15 September 2015/ Accepted: 23 June 2016/Published online: 7 July 2016

(c) The Author(s) 2016. This article is published with open access at Springerlink.com

\begin{abstract}
Photoreception in echinoderms has been known for over 200 years, but their visual capabilities remain poorly understood. As has been reported for some asteroids, the crown-of-thorns starfish (Acanthaster planci) possess a seemingly advanced eye at the tip of each of its 7-23 arms. With such an array of eyes, the starfish can integrate a wide field of view of its surroundings. We hypothesise that, at close range, orientation and directional movements of the crown-of-thorns starfish are visually guided. In this study, the eyes and vision of A. planci were examined by means of light microscopy, electron microscopy, underwater goniometry, electroretinograms and behavioural experiments in the animals' natural habitat. We found that only animals with intact vision could orient to a nearby coral reef, whereas blinded animals, with olfaction intact, walked in random directions. The eye had peak sensitivity in the blue part $(470 \mathrm{~nm})$ of the visual spectrum and a narrow, horizontal visual field of approximately $100^{\circ}$ wide and $30^{\circ}$ high. With approximately 250 ommatidia in each adult compound eye and average interommatidial angles of $8^{\circ}$, crown-of-thorns starfish have the highest spatial resolution of any starfish studied to date. In addition, they have the slowest vision of all animals examined thus far, with a flicker fusion frequency of only $0.6-0.7 \mathrm{~Hz}$. This may be adaptive as fast vision is not
\end{abstract}

Communicated by Biology Editor Dr. Mark J.A. Vermeij

Ronald Petie

ronald.petie@gmail.com

1 Department of Biology, Marine Biological Section, University of Copenhagen, Universitetsparken 4, 2100 Copenhagen $\varnothing$, Denmark

2 Australian Institute of Marine Science, PMB 3, Townsville MC, Townsville, QLD 4810, Australia required for the detection of stationary objects such as reefs. In short, the eyes seem optimised for detecting large, dark, stationary objects contrasted against an ocean blue background. Our results show that the visual sense of the crown-of-thorns starfish is much more elaborate than has been thus far appreciated and is essential for orientation and localisation of suitable habitats.

Keywords Echinodermata $\cdot$ Sensory biology $\cdot$ Eyes $\cdot$ Sea star · Visual ecology

\section{Introduction}

The coral-eating crown-of-thorns starfish Acanthaster planci is probably best known as one of the major causes of coral mortality, with loss of coral cover and community structure shifts through the tropical Indo-Pacific (Pratchett et al. 2010; Osborne et al. 2011; De'ath et al. 2012). Because of the ecological and economic importance of coral reefs, interest in the crown-of-thorns starfish has been increasing in an effort to discover potential mitigation avenues against them. The vast majority of research has focused on the ecology of the crown-of-thorns starfish, the dynamics of population outbreaks, life history (Henderson and Lucas 1971; Zann et al. 1987; Keesing and Lucas 1992; Lamare et al. 2014; Uthicke et al. 2015), larval dispersal and survival (Fabricius et al. 2010; Wooldridge and Brodie 2015), effective culling methods (Grand et al. 2014; Rivera-Posada et al. 2014) and, to a lesser extent, investigations into their toxicity (Lee et al. 2014). However, the sensory biology of the crown-of-thorns starfish remains mostly unstudied.

Three sensory modalities have been documented for starfish: vision, olfaction and mechanosensation 
(Sloan 1980). Starfish are known to use chemoreception to orientate to certain stimuli, especially prey species (Romanes 1883; Kerkut 1953; Beach et al. 1975; Moore and Lepper 1997; Dale 1999), but even this sense is presently poorly understood in the crown-of-thorns starfish. Until now, only a handful of studies have been published specifically on chemoreception by the crownof-thorns starfish, focusing on a spawning pheromone (Beach et al. 1975) and the attraction of crown-of-thorns starfish to extract from corals (Huxley 1976; Ormond et al. 1976) and other feeding cues (Teruya et al. 2001). The olfactory sense in starfish is thought to reside mainly in the terminal tube feet (Dale 1999), but chemical cues can probably be detected by all tube feet. In addition to olfactory stimuli, starfish also respond to mechanical stimuli (Kerkut 1954; Sloan 1980), but this sense has not been studied in detail in any species of starfish.

It has been known for 200 years now that starfish have eye-like structures (Vahl 1780, cited in Smith 1937). The eye consists of a thickening at the base of the unpaired tube foot at the very tip of the arm and resembles a simple compound eye. The function of the starfish eye has only recently been proven for one species of starfish, the blue starfish (Linckia laevigata), which uses its eyes for orientation towards coral reefs (Garm and Nilsson 2014). This starfish has simple compound eyes with about 150 ommatidia. The field of view of the eye covers $170^{\circ}$ vertically and between $120^{\circ}$ and $210^{\circ}$ horizontally, and the average interommatidial angle is $16^{\circ}$. The eyes of L. laevigata are most sensitive to deep blue light of $450 \mathrm{~nm}$. The eye anatomy of Nepanthia belcheri has also been studied in some detail by electron microscopy (Penn and Alexander 1980). This starfish had eyes with about 170 ommatidia.

Orientation to visual stimuli in echinoderms occurs in one species of starfish, L. laevigata (Garm and Nilsson 2014) and two species of sea urchins (Blevins and Johnsen 2004; Yerramilli and Johnsen 2010). In addition, physiological studies have reported phototactic movements in the northern Pacific seastar, Asterias amurensis (Yoshida and Ohtsuki 1966, 1968). Another fascinating example of echinoderm vision is calcite lenses in brittlestars; the only other group of animals with such eyes were the extinct trilobites (Aizenberg et al. 2001; Clarkson et al. 2006; Astley 2012). Calcite eyes should have good image-forming properties, but no behaviour has yet been tied to vision in brittlestars.

In general, animals can use two methods to orient towards visual cues. Sequential sampling of the environment, or phototaxis, would guide the animal along the direction of a light gradient. This process does not, however, require any spatial resolution and could in theory be performed by a single photoreceptor (Dusenbery 1992). Alternatively, if the animal has eyes with multiple photoreceptors that receive light from separate parts of the environment, sampling over time is not required and the animal would get instantaneous information on the light intensity profile and form a true image of its surroundings.

In this paper, we provide a detailed description of the morphology and physiology of the compound eyes of Acanthaster planci. In addition, the importance of vision is confirmed by behavioural experiments in the natural habitat. We tested the hypotheses that (1) crown-of-thorns starfish rely on vision for close-range orientation towards coral reefs and (2) the eyes are well adapted to seeing coral reefs.

\section{Materials and methods}

\section{Morphology}

\section{General morphology}

Pictures of the eyes were taken in vivo using a Nikon D300 camera equipped with a 105-mm Micro-Nikkor lens and also with a Leica dissection microscope equipped with a digital camera (Evolution MP 5.0, Media Cybernetics, MD, USA).

\section{Eye size}

The 12 animals used for the eye size measurements were collected from several reefs near Cairns, Australia, in May 2015 and transported to the Australian Institute of Marine Science in Townsville by the Australian Marine Parks Tourist Operators crown-of-thorns starfish control programme. They were kept in holding tanks supplied with running, filtered sea water at a temperature of $27^{\circ} \mathrm{C}$. In captivity, the starfish were not fed and were used within 3 weeks of collection. Eye dimensions were measured, and ommatidia were counted manually from images taken through a stereo microscope. For this experiment, the animals ranged in diameter from 1.5 to $38 \mathrm{~cm}$, measured under water.

\section{Electron microscopy}

Three eyes from three separate specimens collected off the coast of Cairns, Australia ( $\left.16^{\circ} 50^{\prime} 50.82^{\prime \prime} \mathrm{S}, 146^{\circ} 13^{\prime} 37.92^{\prime \prime} \mathrm{E}\right)$, in April 2014, were used for transmission electron microscopy. Eyes were fixed in $2.5 \%$ glutaraldehyde, $1.5 \%$ paraformaldehyde and $3 \%$ sucrose in $0.1 \mathrm{M}$ phosphatebuffered saline (PBS) buffer overnight. The eyes were postfixed in $1 \%$ osmium tetroxide in $0.1 \mathrm{M}$ PBS overnight at $4{ }^{\circ} \mathrm{C}$, dehydrated in a series of ethanol and acetone, embedded in Epon 812 resin following standard procedures and contrasted with lead citrate and uranyl acetate. The 70-nm-thick sections were observed in a JEOL 1010 
transmission electron microscope (JEOL, Tokyo, Japan) equipped with a SC1000 Gatan digital camera (Gatan, Pleasanton, CA, USA). Longitudinal sections of five randomly chosen, fully developed ommatidia were used to measure ommatidial size and receptive fields.

\section{Screening pigment}

The spectral properties of the red screening pigment were measured on a squash preparation of an eye using a spectroradiometer (ILT900 W, International Light Technologies Inc., Peabody, MA, USA) and a compound microscope. A fresh eye was used from a specimen collected off the coast of Cairns, Australia, and shipped to Denmark in January 2016. After arrival, the starfish was kept at the Danish National Aquarium, The Blue Planet, in a $12,000-\mathrm{L}$ tank with recycling sea water with a salinity of $33 \%$ and a temperature $26.5{ }^{\circ} \mathrm{C}$. The squash preparation was viewed in a compound microscope and arranged such that the red pigment took up most of the visual field. The relative absorption curve was calculated from the difference in the spectra of the unfiltered background light compared to the light that travelled through the red screening pigment, measured with the spectroradiometer.

\section{Goniometry}

In the compound eye of the crown-of-thorns starfish, each eyelet (ommatidium) collects light from different areas in space; these differences in viewing direction can be expressed in angles and measured by a goniometer (angle measurement tool). Five eyes of three individuals collected in Cairns in April 2014 and fixed in 4\% paraformaldehyde in 0.15 M PBS buffer were used for the goniometry measurements. The eye of the crown-of-thorns starfish is bilaterally symmetrical, as is that of L. laevigata; therefore, only one of the two halves of each eye was measured. The optical axes of six evenly spaced ommatidia around the perimeter of the eye-half were measured to determine the edges of the visual field. To measure the angles between ommatidia, or interommatidial angle, two ommatidia were randomly picked from each eye and the angles between the optical axis of each chosen ommatidium, as well as the optical axes of its nearest neighbours, were measured. Seventy-three angles were measured, and seven outliers were removed that had interommatidial angles greater than $20^{\circ}$.

\section{Electrophysiology}

\section{Animals}

Animals for the physiological experiments were collected either on coral reefs in Indonesia or on the Great Barrier
Reef near Cairns, Australia. The animals from Australia were flown to Denmark in April 2014 and February 2015. The animals from Indonesia were transported to Denmark in May 2015. The starfish varied in size between 10 and $40 \mathrm{~cm}$ in diameter, measured underwater, from arm tip to arm tip, not including the spines. The animals were fed a fish-based gel every second day and were used for experiments within 6 months.

The starfish were taken from the holding tank at The Blue Planet in the morning and transported for approximately $30 \mathrm{~min}$ to the University of Copenhagen in a styrofoam box containing sea water. After the experiments, the animals were returned to The Blue Planet. The electrophysiology experiments were performed between November 2014 and July 2015. The ambient temperature of the set-up was $25^{\circ} \mathrm{C}$. For the experiments with flash stimulation, seven eyes from four animals were used. For the flicker fusion frequency experiments, eight eyes from four different animals were used.

\section{Protocol}

Three electrophysiological experiments were performed. First, the absolute sensitivity of the eye to light was tested by stimulating the eye with $100 \mathrm{~ms}$ flashes of light of varying intensity. Second, as a part of the previous testing sequence, the colour of the light flashes was changed to test the eye's spectral sensitivity. Third, the temporal resolution was determined by means of a flicker fusion experiment. In this experiment, a light was presented to the eye with a sinusoidally modulated intensity. The photoreceptors can perceive the changes in light intensity up to the so-called flicker fusion frequency.

Eyes were removed from the animals using fine scissors and placed into a Petri dish containing sea water. The extracellular electrode was attached to an ommatidium using suction, and the reference electrode was placed in the bath of sea water. All electrophysiological measurements were taken with 90-120 s rest between stimulation to prevent photoreceptor adaptation.

Prior to the flicker fusion experiments, the eye was adapted to mid-intensity $\left(1.3 \times 10^{2} \mathrm{~W} \mathrm{sr}^{-1} \mathrm{~m}^{-2}\right)$ white light for $15 \mathrm{~min}$ after which the eye was exposed to light with a sinusoidally modulated light intensity for $60 \mathrm{~s}$ when data were recorded.

For experiments using flash stimulation, the eye was dark adapted for $30 \mathrm{~min}$ before the experiment and the experiments were performed in darkness. The duration of the light flashes used was $100 \mathrm{~ms}$, and data were recorded for $5 \mathrm{~s}$.

All recordings were amplified a thousand times, filtered with a $50-\mathrm{Hz}$ notch filter and a $0.1-\mathrm{Hz}$ high-pass filter together with a $1-\mathrm{kHz}$ low-pass filter on a DC1700 differential amplifier (AM Systems Inc., WA, USA). The 
signals were digitised at $1 \mathrm{kHz}$ using a NI USB-6229 DAQ card (National Instruments, TX, USA), which was controlled by a custom-made LabVIEW program (National Instruments, TX, USA).

As a stimulus, a Luxeon LXHL-LW6C LED (Philips, San Jose, CA, USA) was used for the flicker fusion frequency experiments and a Luminus CBT-90 LED (Luminus, Sunnyvale, CA, USA) for the flash stimulation. Light intensity was controlled with neutral density filters in steps of 0.3 or $0.7 \log$ units, and the wavelength was controlled using interference colour filters (half width $=12 \mathrm{~nm}, \mathrm{CVI}$ Laser, Bensheim, Germany) in steps of 10 or $20 \mathrm{~nm}$. Light was transferred to the eye using a 1-mm light guide ensuring a close-to-even illumination of the entire eye. At full power, the light intensity at the exit of the light guide during the flicker fusion experiments was $2.5 \times 10^{2} \mathrm{~W}$ $\mathrm{sr}^{-1} \mathrm{~m}^{-2}$. For the spectral sensitivity experiments, the eyes were stimulated with equal quanta light pulses at $1.7 \times 10^{19}$ photons $\mathrm{s}^{-1} \mathrm{sr}^{-1} \mathrm{~m}^{-2}$.

\section{Analysis}

The flash response recordings were analysed manually in the program Igor Pro 7 (Wavemetrics, Lake Oswego, OR, USA). In contrast to linear models where the $R^{2}$ is commonly used, the goodness of fit for nonlinear models is best described by Akaike's information criterion (AIC) (Spiess and Neumeyer 2010). This measure was used to determine the goodness of fit of the opsin template to the spectral sensitivity curve.

The flicker fusion frequency was calculated from the frequency composition of the signal using a fast Fourier transform in R, version 3.2.1 (R Development Core Team 2012) on RStudio (version 0.98.1103). Care was taken that for each experiment the analysed fragment of the recording contained an equal number of six cycles. Therefore, the length of the analysed fragments varied with stimulation frequency; however, they were always chosen to start at the onset of stimulation. The strength of the response was taken as the power of the Fourier transform at the principle frequency of stimulation.

\section{Behavioural experiments}

To determine whether the crown-of-thorns starfish uses vision to locate coral reefs, intact, blinded and sham-operated starfish were placed approximately $1 \mathrm{~m}$ away from a reef off the coast of Cairns, Australia $\left(16^{\circ} 50^{\prime} 50.82^{\prime \prime} \mathrm{S}\right.$, $\left.146^{\circ} 13^{\prime} 37.92^{\prime \prime} \mathrm{E}\right)$. The animals were blinded by removing the eye. Note that this does not affect the chemosensory sense since no other tube feet were affected. The shamoperated animals functioned as a control experiment. These animals received a surgical treatment, just like the blinded animals, but two tube feet from the middle of each arm were removed. The putatively olfactory tube feet at the arm tips were unaffected. The starfish eye is a modified tube foot, so removing tube feet is surgically a similar procedure to removing eyes. Initially, ten intact animals were tested; the same ten animals were used for experiments with blinded animals, making these two experiments paired. After the surgery, the animals were allowed to recover for one day. Seven new individuals were used for the experiments with sham-operated animals. All test animals were collected on the test reef the day before their initial experiments, and they varied between 10 and $17 \mathrm{~cm}$ in diameter, measured underwater.

The starfish were tested in groups of up to five individuals. The position of the animals was recorded every min for 5-8 min from digital images (GoPro Hero 2, San Mateo, California, USA). The angle between the reef, the starting position and the final position of the animal was taken as the overall direction of movement. The speed of locomotion was calculated from the displacement of the animal between images. If an animal reached the reef, the point where the animal contacted the reef was used as the final position of the animal. In all experiments, the direction perpendicular to the reef front was set to $0^{\circ}$. The walking trajectories obtained were also used to determine the walking speed for each animal. For statistical analysis, the walking directions were tested with circular statistics (Rayleigh test) and the walking speeds were compared using an analysis of variance (ANOVA), treating the data for the intact and blinded treatment group as unpaired.

\section{Results}

\section{Eye morphology}

The eyes of the crown-of-thorns starfish are simple compound eyes located at the tips of the arms. Each arm has one eye (Fig. 1a, b). The eye moves as the animal moves its arm, and in addition, the eye is positioned on a moveable knob which extends the range of motion even further. The eye sits at the base of a modified tube foot (Fig. 1b) and is often referred to as the optical cushion. The ommatidia are clearly visible by their bright red screening pigment (Fig. 1c).

The size of the eyes increased with the size of the animal. For the size range of the animals used, a linear increase (Fig. 2a) in the number of ommatidia was found $\left(F_{1,10}=75.37, p<0.001, R^{2}=0.87\right)$. For the smallest animal, which was $1.5 \mathrm{~cm}$ in diameter, the length and width of the eye were approximately equal; however, as the animals increased in size the length of the eye increased more than the width (Fig. 2b). The increase in both width 

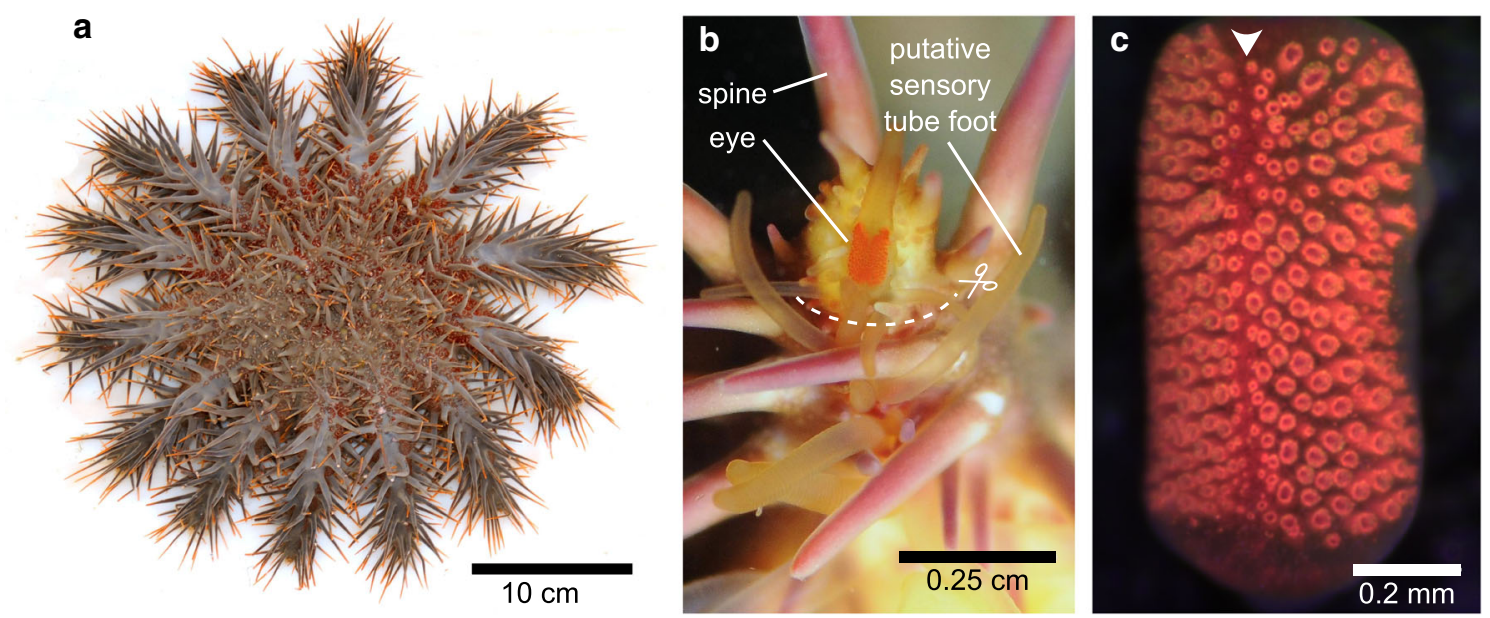

Fig. 1 a Crown-of-thorns starfish, Acanthaster planci. b The eyes are located at the tips of the arms. The dotted line indicates where the eye was cut for behavioural and electrophysiological experiments. c The

$\left(F_{1,10}=147.5, \quad p<0.001, \quad R^{2}=0.93\right) \quad$ and length $\left(F_{1,10}=67.6, p<0.001, R^{2}=0.86\right)$ of the eye was described well by a linear model.

The ommatidia from five eyes of three individuals, $35-38 \mathrm{~cm}$ in diameter, had a mean width (measured from the outside of the screening pigment) of $25 \mu \mathrm{m}(\mathrm{SD}=6.4$, $n=5)$ and a mean depth of $83 \mu \mathrm{m}(\mathrm{SD}=9.3, n=5$; Fig. 3a). The surface of the ommatidia was curved (Fig. 3c); however, no lens-like structures were observed and the acceptance angles of the ommatidia are thus set by shading from the screening pigment only. Thus, from the
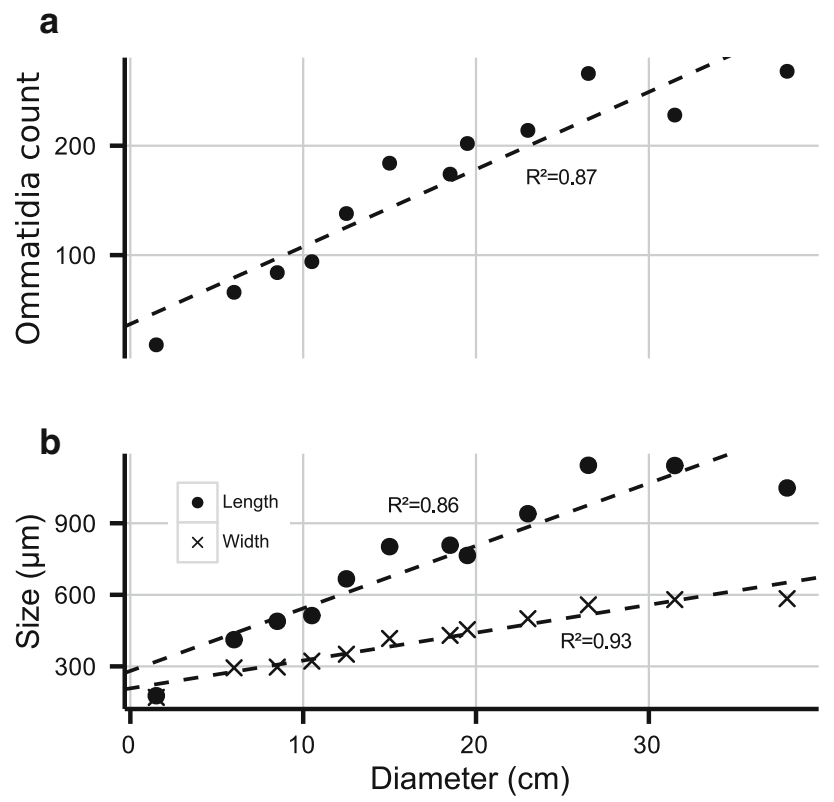

Fig. 2 a Relationship between the number of ommatidia (eyelets) per eye and the diameter of the animal. b Relationship between length (circles) and width (crosses) of the eye and the diameter of the animal eye is a simple compound eye situated on a modified tube foot. The arrowhead points out the mid-line of the eye. The screening pigment of the ommatidia is red

bottom of the ommatidium, the acceptance angle was $15^{\circ}$ $(\mathrm{SD}=6.7, n=5)$, but $38^{\circ}(\mathrm{SD}=15, n=5)$ from the middle of the ommatidium. The outer segments of the photoreceptors were made from both a modified cilium and from microvilli from the cell membrane (Fig. 3b, d). The red screening pigment in the eye absorbed light best up to a wavelength of $550 \mathrm{~nm}$, after which light absorption decreased (Fig. 4).

\section{Goniometry}

Five eyes from three individuals sized between 35 and $38 \mathrm{~cm}$ were used, and the field of view of the entire eye could be approximated by an ellipse (Fig. 5). The mean ellipse had a width of $102^{\circ}(95 \%$ confidence interval $\left.=21^{\circ}, n=5\right)$ and a height of $31^{\circ}$ (95\% confidence interval $=15^{\circ}, n=5$ ). The mean angle between ommatidia measured $8^{\circ}\left(\mathrm{SD}=4.5^{\circ}, n=66\right.$; Fig. 5).

\section{Electrophysiology}

The photoreceptors in the retina responded to a flash of light by a bi-phasic graded potential, followed by a return to the resting potential (Fig. 6a). The intensity tuning curve, or V-logI curve (Fig. 6b), shows that in the range of intensities used the photoreceptors did not saturate. Accordingly, the full dynamic range could not be determined but it is at least three log units. The eyes were found to be most sensitive to blue light of $470 \mathrm{~nm}$, and the bestfitting opsin had a peak at $472 \mathrm{~nm}$ (Fig. 6c). Both the wavelength of the opsins' $\alpha$ peak and the amplitude of the curve were varied to find the best fit. The AIC for this opsin fit was -37.3 . Note that more negative values reflect a better model fit. 

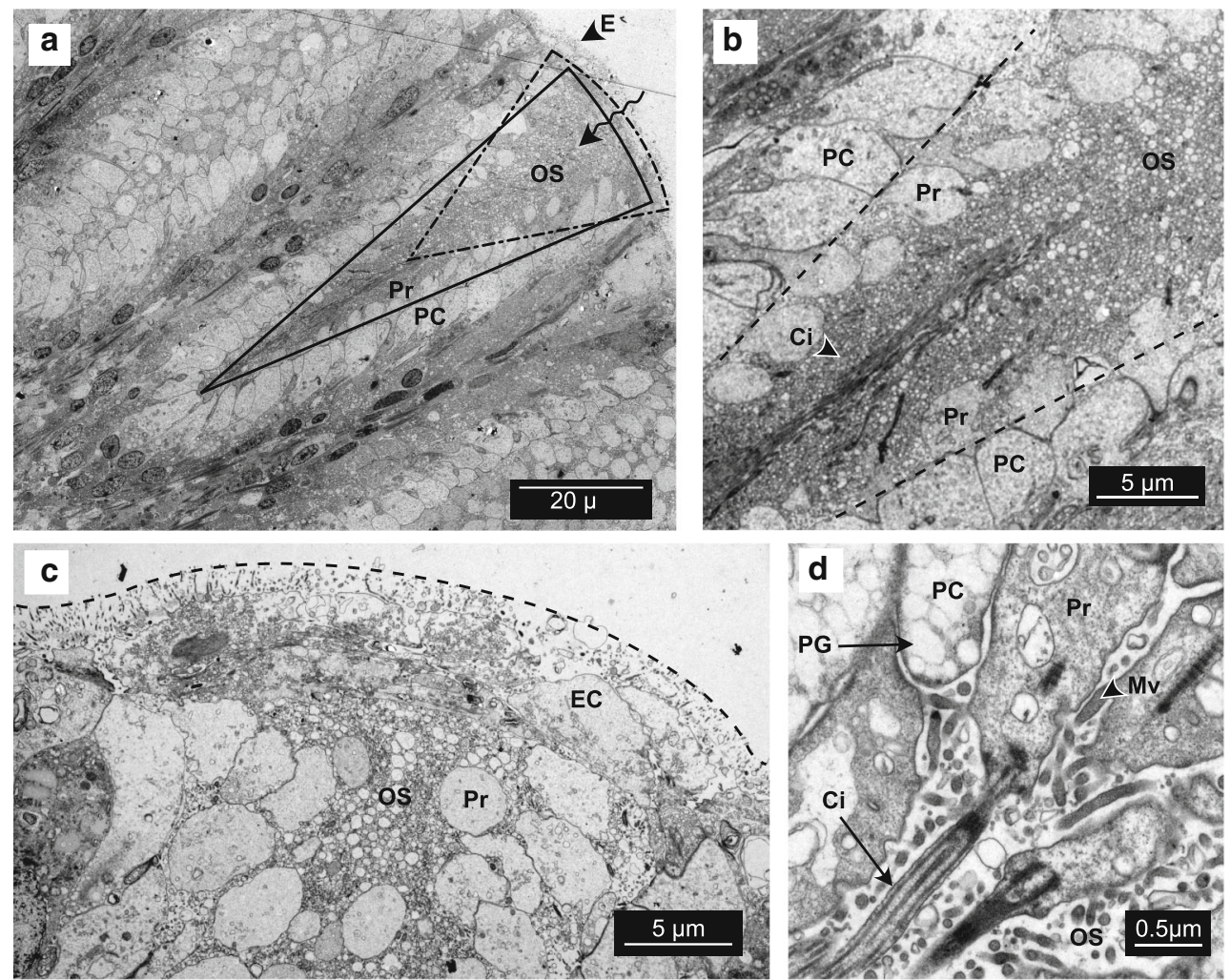

Fig. 3 a The compound eye of a crown-of-thorns starfish is divided up in many smaller eyelets (ommatidia). Light detected by this ommatidium comes from the top right (wavy arrow), passes the epithelium (E) and is captured by the outer segments (OS) of the photoreceptors (Pr). Photons not absorbed by the outer segments are absorbed by the screening pigment in the pigment cells (PC). Shielding by the pigment cells determines the direction and angle from which light is sampled. Solid lines indicate the light acceptance angles from the bottom of the ommatidium, while the dash-dot lines

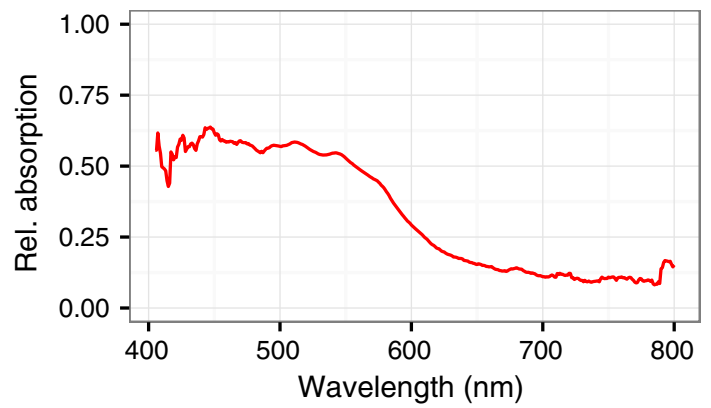

Fig. 4 Relative absorption curve for the red screening pigment in the eye of the crown-of-thorns starfish

The strength of the responses to a sinusoidally flickering stimulus decreased with increasing stimulation frequency (Fig. 7). Using a threshold value for the flicker fusion frequency of $10 \%$ of the strongest response, the eye of the indicate the light acceptance angles from the middle of the ommatidium. b Close-up of the previous image showing cilia (Ci). The dashed line indicates the boundary between pigmented and nonpigmented cells. c The curved epithelium covering the ommatidium (dashed line). Note the absence of lens-like structures. d The photoreceptors are of a structurally mixed type, with the outer segments formed both by microvilli (Mv) from the cell membrane and by a cilium $(\mathrm{Ci})$

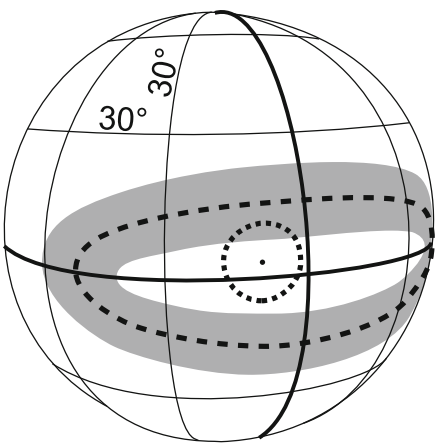

- - Eye receptive field, mean $\pm 95 \% \mathrm{Cl}$ .... Interommatidial angle

Fig. 5 Mean receptive field of the eye (ellipse) and the interommatidial angle (circle) shown projected on the surface of a sphere, with the eye in the centre of the sphere $(n=5$ eyes; $95 \%$ confidence interval in grey) 

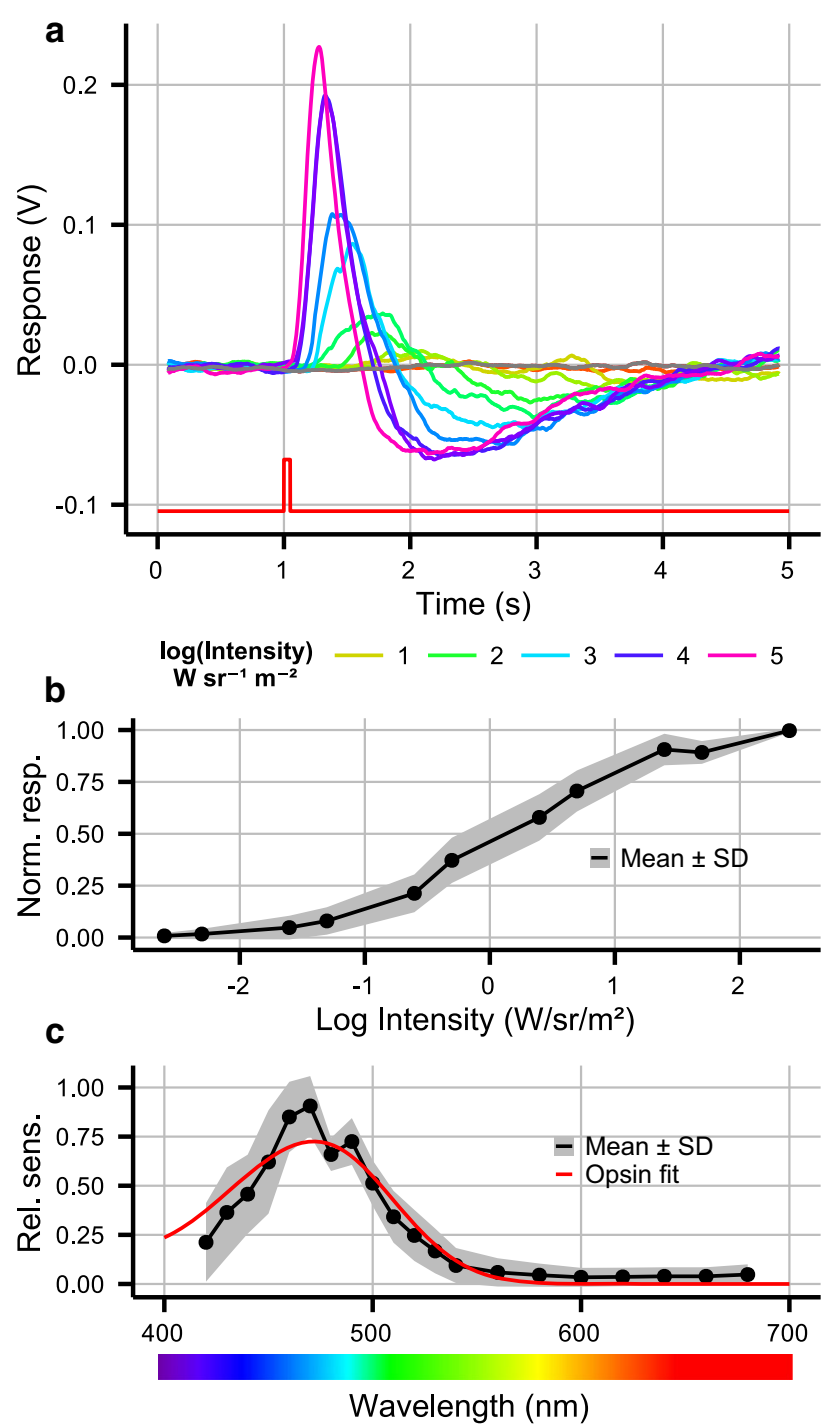

Fig. 6 a Responses to flashes of white light with increasing intensity, filtered with a centred running average of $160 \mathrm{~ms}$. The bottom red trace shows the timing of the flash in arbitrary units. b The intensity tuning curve, or V-LogI curve for crown-of-thorns starfish eyes $(n=7)$. c Spectral sensitivity of the eye (black line, $n=7)$. The bestfitting opsin template is shown by the red line. Standard deviation in grey shading

crown-of-thorns starfish had a flicker fusion frequency between 0.6 and $0.7 \mathrm{~Hz}$ (Fig. 7d).

\section{View of natural scenes}

The original image of a coral reef (Fig. 8a) was compared to the view away from the reef (Fig. 8b). Our electrophysiology results showed that the eyes are most sensitive to blue light. Hence, the light intensities perceived by the crown-of-thorns starfish can be approximated by taking the pixel intensities in the blue channel of the colour images (Fig. 8c, d). When applying a Gaussian blur filter with an
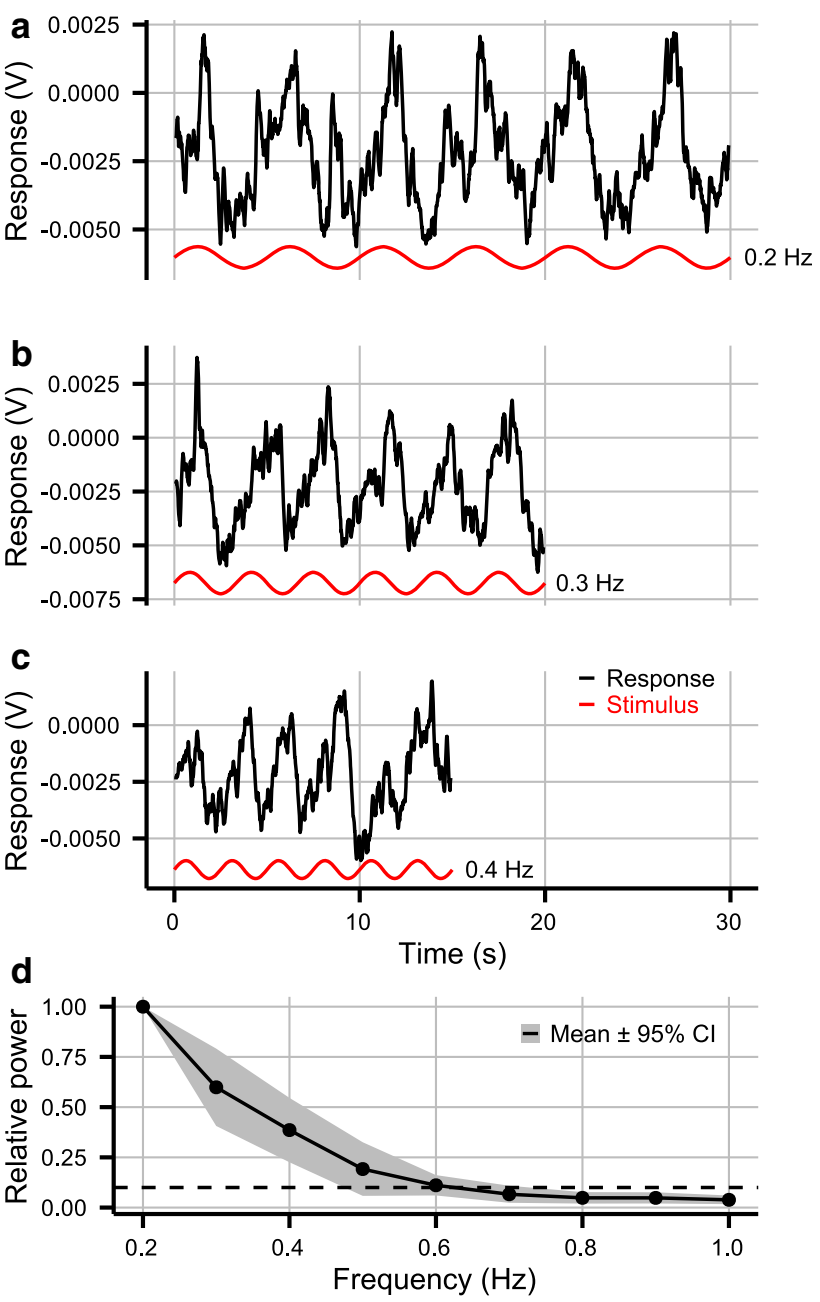

Fig. 7 a-c Responses of crown-of-thorns starfish eyes subjected to light flickering in a sinusoidal pattern at different stimulation frequencies. The bottom traces, in red, indicate the stimulation pattern in arbitrary units, and the black traces show the electrical response of the photoreceptors. Response curves were made applying a centred running average of $160 \mathrm{~ms}$ to the data. The frequency composition of the original, un-averaged, response was used to determine the strength of the response. $\mathbf{d}$ Relationship between the stimulation frequency and the strength of the response $(n=8$; mean in black, 95\% confidence interval in grey shading). The threshold for the flicker fusion frequency was set to $10 \%$ of the maximal response (dashed line)

$8^{\circ}$ radius, to simulate the spatial resolution of the eye, the coral reef scene is still detectable (Fig. 8e), while nearly all contrast is gone in the view away from the reef (Fig. 8f).

\section{Behavioural experiments}

The behavioural data showed that both intact starfish and the sham-operated control group were able to orient back to the reef when placed $1 \mathrm{~m}$ outside a reef (Fig. 9). In contrast, blinded animals were not able to orient back to the reef and walked in random directions. The average walking 

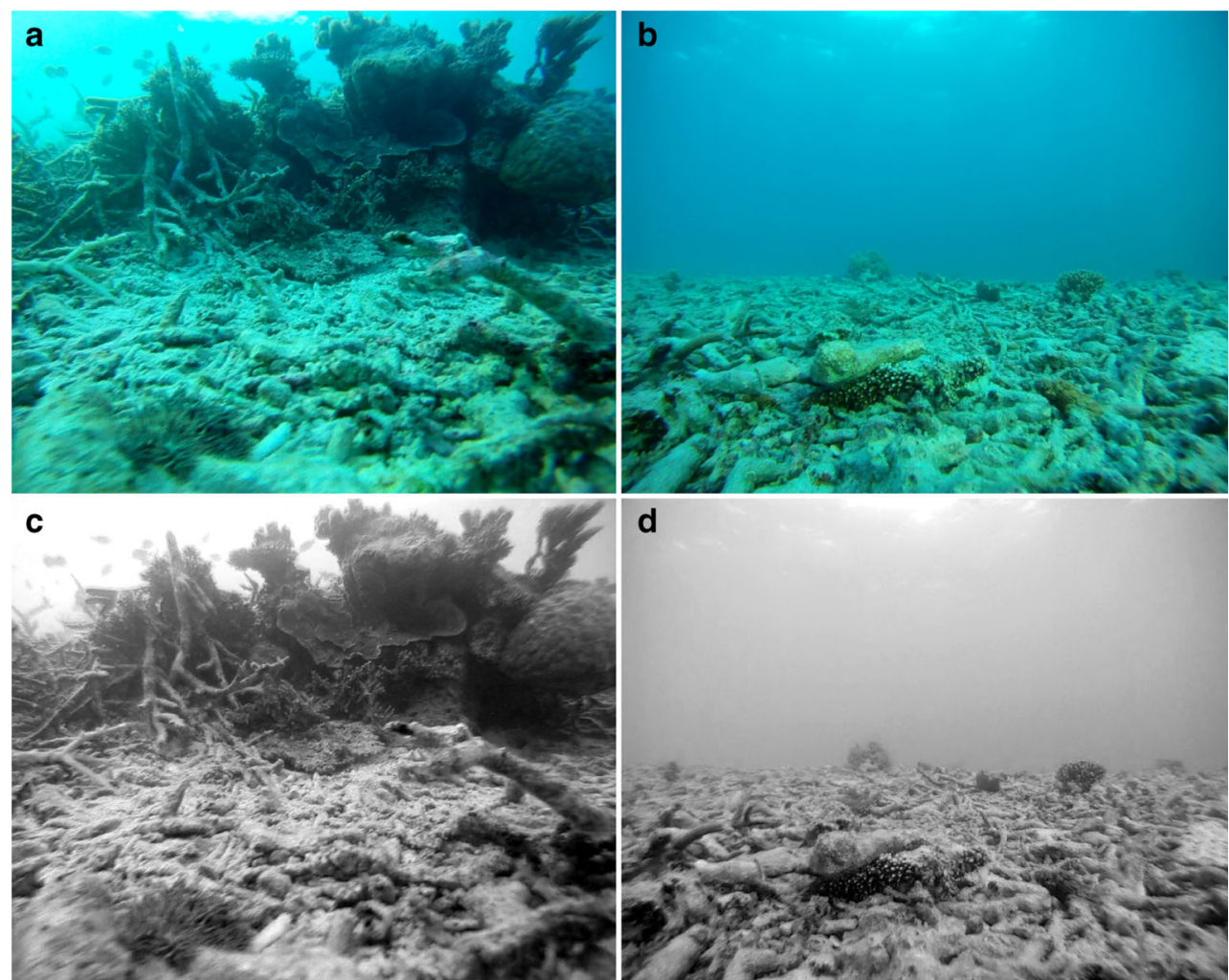

d

e

f

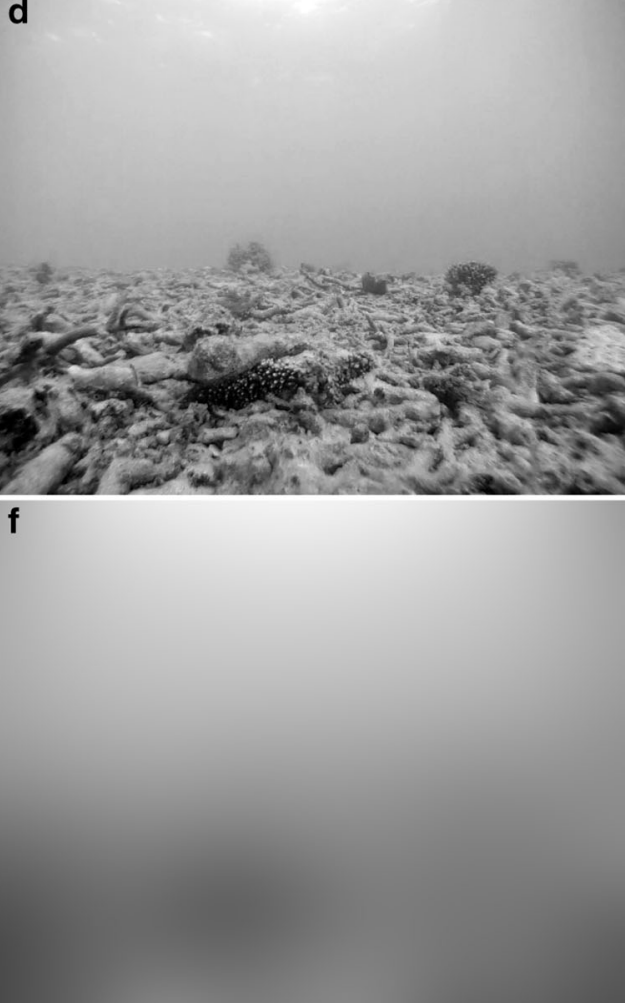

Fig. 8 Underwater images showing a view towards the reef a and towards the open ocean b. c, $\mathbf{d}$ The same views showing only the blue channel. e, f The same images filtered with a Gaussian blur filter with

an $8^{\circ}$ radius to simulate the sampling frequency of the eyes of the crown-of-thorns starfish

speed was between 7.5 and $11.0 \mathrm{~cm} \mathrm{~min}^{-1}$, and there was no significant difference in speed among the three different experiments (one-way ANOVA, $F_{2,24}=1.52, p=0.24$ ).

\section{Discussion}

We set out to investigate the quality and role of vision in the sensory biology of the crown-of-thorns starfish and found that vision is crucial for their ability to locate reef structures at short distances. Without vision, crown-ofthorns starfish were not able to locate the reef, but

wandered in random directions. In addition, we found that visual information was heavily filtered by the eye, enabling the animals to see large, dark, inanimate objects, like coral boulders, against a blue background best. The methods used in this study and the results obtained closely resemble those of a previous study (Garm and Nilsson 2014) on $L$. laevigata.

\section{Finding coral reefs}

Unlike in the terrestrial world, long-range visual orientation cues are not feasible in the marine environment. Even 


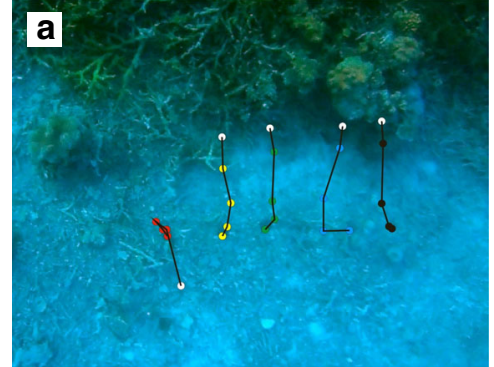

Fig. 9 a Five example tracks of intact crown-of-thorns starfish, placed $1 \mathrm{~m}$ in front of a coral reef. Black lines indicate the tracks, different coloured circles are used to indicate the positions of individual animals, and the white circles mark the final position for all animals. b The homing behaviour of intact, sham-operated and

in the clearest ocean water, the visual range is rarely greater than $40 \mathrm{~m}$ (Lythgoe 1968), declining rapidly with increasing concentrations of visual impurities in the water. For long-range detection, animals have to rely on another sense, which would likely be olfaction. Successful longdistance navigation by means of olfaction has been found in birds (Gagliardo et al. 2013), fish (Keefer and Caudill 2013) and crabs (Weissburg and Zimmer-Faust 1994). Although olfaction is a well-developed sense in many marine benthic invertebrates, it is much less accurate as a directional homing cue in the presence of boundary layer turbulence (Weissburg and Zimmer-Faust 1993), which can be found close to large structures like coral reefs. At close quarters, visual detection can provide the animals with a reliable cue and is believed to be used by crown-ofthorns starfish to settle on reefs (Pratchett et al. 2014). This claim is supported by our observation that both intact and sham-operated animals found coral reefs, whereas blinded animals did not. This confirms the idea that in some cases vision can be the dominant sensory modality in starfish, despite the focus of previous studies (Romanes 1883; Moore and Lepper 1997; Dale 1999) on olfactory orientation.

If it is unlikely that crown-of-thorns starfish migrate to other reefs after initial settlement as larvae, as some authors suggest (Bos et al. 2013), vision could provide the starfish with reliable homing cues for staying within the structure of the reef. If starfish wander off the reef, the clear difference in the view towards the reef and into the ocean would provide an unmistakable orientation landmark for directing the starfish back to the reef (Fig. 8).

\section{Properties of the visual system}

The behavioural data show that the eyes of the crown-ofthorns starfish can be used for orientation towards large inanimate objects and are essential for short-range blinded starfish. The reef is located at the top of the image, at $0^{\circ}$. The statistical values are for the Rayleigh test. When $p$ values are significant, the $95 \%$ confidence interval is indicated by the dashed lines

detection of coral reefs. The low-resolution vision that crown-of-thorns starfish have is more than sufficient for orientation towards large immovable objects (Nilsson 2013). Orientation towards large inanimate objects could also be accomplished by animals that have directional photoreception, a form of vision without spatial resolution. For directional photoreception to be effective, the animal needs to make scanning movements to find the direction of greatest darkness. This poses the question why the crownof-thorns starfish has such well-developed functional eyes and a combined visual field that spans the entire circumference of the animal. Likely, visual orientation can be accomplished faster and more accurately, without the necessity for scanning movements. The average interommatidial angle of $8^{\circ}$ puts the resolution of the crown-ofthorns starfish in the range of the $4.6^{\circ}$ found in Drosophila (Borst 2009) while it is better than the $16^{\circ}$ found in the blue starfish L. laevigata (Garm and Nilsson 2014).

The crown-of-thorns starfish does not move very fast and has a maximum speed of only $51 \mathrm{~cm} \mathrm{~min}^{-1}$ (Mueller et al. 2011). This lowers the requirements for temporal resolution of vision, which is particularly slow in this benthic invertebrate. The flicker fusion frequency lies between 0.6 and $0.7 \mathrm{~Hz}$. To our knowledge, this makes the eyes of the crown-of-thorns starfish the slowest eyes described in the animal kingdom so far, slower even than the approximately $5 \mathrm{~Hz}$ found in toads (Toyoda and Coles 1975), the $2.5 \mathrm{~Hz}$ found for box jellyfish Copula sivickisi (Garm et al. 2016) and the $8 \mathrm{~Hz}$ found in another box jellyfish, Tripedalia cystophora (O'Connor et al. 2010a).

The first indication of the spectral sensitivity of the animal is the colour of the screening pigment, which is bright red (Fig. 1). This implies that vision will be most effective outside the red region of the spectrum. Allowing ommatidia to sample different areas in space by means of pigmentation is the simplest way to give an eye spatial resolution. The screening function will only be effective in 
short wavelength light, since this is best absorbed by the red pigment (Fig. 4). The spectral sensitivity data confirm this initial observation. The sensitivity of the eyes peaked at $470 \mathrm{~nm}$ and the best-fitting opsin template (Govardovskii et al. 2000) had peak sensitivity at $472 \mathrm{~nm}$. Corals, in particular brown ones (Schalles et al. 2000; Hochberg et al. 2004), would have a high contrast against the ocean blue background (Fig. 8) and would be easiest to detect visually by starfish. As found in L. laevigata, the measured spectral sensitivity curve was narrower than the opsin template (Garm and Nilsson 2014). It could be that the damaging ultraviolet rays are filtered out by the eye, thereby narrowing the spectral sensitivity curve at the blue end of the spectrum (O'Connor et al. 2010b). The eye is covered by a thin layer of epithelial cells (Fig. 3a), but at this stage it is unknown whether this layer could be responsible for removing ultraviolet light.

The relatively large variation in the size and acceptance angles of the ommatidia could be an adaptation to expand the sensitivity range of the eye. Larger ommatidia would be more sensitive to light because they can gather more photons and provide image information in dim conditions, whereas the smaller ommatidia are less sensitive and would function well in bright conditions, when the larger ommatidia are saturated. A similar variation in ommatidia size has been coupled to an expanded sensitivity range in the common backswimmer, Notonecta glauca (Immonen et al. 2014). Alternatively, the low resolution of the eye could allow for a relatively large variation in the acceptance angles of the ommatidia without a noticeable loss of image quality.

The visual field of the eye seems to be optimised for viewing objects in a narrow region around the horizon. A similar focus is found in animals that inhabit an environment where the important visual features are on the horizon, such as crabs (Zeil et al. 1986), water striders (Dahmen 1991), rabbits (Chievitz 1891) and benthic fish (Collin and Pettigrew 1988). In fact, a similar elongated eye shape can be observed in both fiddler crabs (Zeil et al. 1986) and crown-of-thorns starfish (Fig. 1c), giving both species high resolving power in the vertical axis, optimising detection of features on the horizon. The overlapping fields of view between the eyes could, in theory, give the animal depth perception. Depth perception could also be accomplished by lateral movements (Land and Nilsson 2012); however, these were not observed in crown-ofthorns starfish. Finally, the position of the eyes on the arms could potentially give the animal a high degree of control over viewing direction in space and time.

\section{Possibilities for trapping}

One of the management strategies used to control population outbreaks is the culling of millions of crown-of-thorns starfish by lethal injection by divers. It is a labour-intensive activity, and efforts are being made to optimise the process (Bos et al. 2013). In addition, research is being done to develop more effective poisons that kill the crown-ofthorns starfish with the least number of injections while leaving other organisms unharmed (Rivera-Posada et al. 2014). The culling process could be facilitated further by concentrating the animals in a limited area or by trapping them. Crown-of-thorns starfish probably use multiple sensory cues to find their coral prey, as search strategies are often more accurate when they use more than one sensory modality (Sheynikhovich et al. 2012). The data we have presented here could be used to construct artificial structures that look and smell "right" to the crown-of-thorns starfish and act as bait or at least as an attraction device. Animals concentrated in and around such structures could then be killed by injections; alternatively, the entire structure could be lifted up and emptied on a boat. Crownof-thorns starfish have been trapped using solely olfactory stimuli (Teruya et al. 2001), and adding a visual stimulus could improve the procedure.

Acknowledgments We would like to thank Daniel Pedersen from the Danish National Aquarium, The Blue Planet, for his assistance with the experiments in Australia, Prof. Dan-Eric Nilsson, Lund University, for letting us use his underwater goniometer and Lis Munk Frederiksen, University of Copenhagen, for her assistance preparing for the electron microscopy. This work was supported by the Danish Council for Independent Research I Natural Sciences (4002-00284 to RP) and by the Carlsberg Foundation (Grant \#2013_01_0251 to AG).

Open Access This article is distributed under the terms of the Creative Commons Attribution 4.0 International License (http://crea tivecommons.org/licenses/by/4.0/), which permits unrestricted use, distribution, and reproduction in any medium, provided you give appropriate credit to the original author(s) and the source, provide a link to the Creative Commons license, and indicate if changes were made.

\section{References}

Aizenberg J, Tkachenko A, Weiner S, Addadi L, Hendler G (2001) Calcitic microlenses as part of the photoreceptor system in brittlestars. Nature 412:819-822

Astley HC (2012) Getting around when you're round: quantitative analysis of the locomotion of the blunt-spined brittle star, Ophiocoma Echinata. J Exp Biol 215:1923-1929

Beach DH, Hanscomb NJ, Ormond RFG (1975) Spawning pheromone in crown-of-thorns starfish. Nature 254:135-136

Blevins E, Johnsen S (2004) Spatial vision in the echinoid genus Echinometra. J Exp Biol 207:4249-4253

Borst A (2009) Drosophila's view on insect vision. Curr Biol 19:R36-R47

Bos AR, Gumanao GS, Mueller B, Saceda-Cardoza MME (2013) Management of crown-of-thorns sea star (Acanthaster planci L.) outbreaks: removal success depends on reef topography and timing within the reproduction cycle. Ocean Coast Manage $71: 116-122$ 
Chievitz JH (1891) Über das Vorkommen der Area centralis retinae in den vier höheren Wirbelthierklassen. Archiv für Anatomie und Physiologie 139:311-334

Clarkson E, Levi-Setti R, Horváth G (2006) The eyes of trilobites: the oldest preserved visual system. Arthropod Struct Dev 35:247-259

Collin SP, Pettigrew JD (1988) Retinal topography in reef teleosts II. Brain Behav Evol 31:283-295

Dahmen H (1991) Eye specialisation in waterstriders: an adaptation to life in a flat world. J Comp Physiol A Neuroethol Sens Neural Behav Physiol 169:623-632

Dale J (1999) Coordination of chemosensory orientation in the starfish Asterias forbesi. Mar Freshw Behav Physiol 32:57-71

De'ath G, Fabricius KE, Sweatman H, Puotinen M (2012) The 27-year decline of coral cover on the Great Barrier Reef and its causes. Proc Natl Acad Sci U S A 109:17995-17999

Dusenbery DB (1992) Sensory ecology: how organisms acquire and respond to information. W. H. Freeman and Company, New York

Fabricius KE, Okaji K, De'ath G (2010) Three lines of evidence to link outbreaks of the crown-of-thorns seastar Acanthaster planci to the release of larval food limitation. Coral Reefs 29:593-605

Gagliardo A, Bried J, Lambardi P, Luschi P, Wikelski M, Bonadonna F (2013) Oceanic navigation in Cory's shearwaters: evidence for a crucial role of olfactory cues for homing after displacement. J Exp Biol 216:2798-2805

Garm A, Nilsson D-E (2014) Visual navigation in starfish: first evidence for the use of vision and eyes in starfish. Proc R Soc Lond B Biol Sci 281:20133011

Garm A, Bielecki J, Petie R, Nilsson D-E (2016) Hunting in bioluminescent light: vision in the nocturnal box jellyfish Copula sivickisi. Front Physiol 7:1-9

Govardovskii VI, Fyhrquist N, Reuter T, Kuzmin DG, Donner K (2000) In search of the visual pigment template. Vis Neurosci 17:509-528

Grand A, Pratchett M, Rivera-Posada J (2014) The immune response of Acanthaster planci to oxbile injections and antibiotic treatment. J Mar Biol 2014:e769356

Henderson JA, Lucas JS (1971) Larval development and metamorphosis of Acanthaster planci (Asteroidea). Nature 232:655-657

Hochberg EJ, Atkinsonn MJ, Apprill A, Andréfouët S (2004) Spectral reflectance of coral. Coral Reefs 23:84-95

Huxley CJ (1976) Response of Acanthaster planci (L.) to partial stimuli. J Exp Mar Bio Ecol 22:199-206

Immonen E-V, Ignatova I, Gislen A, Warrant E, Vähäsöyrinki M, Weckström M, Frolov R (2014) Large variation among photoreceptors as the basis of visual flexibility in the common backswimmer. Proc R Soc Lond B Biol Sci 281:20141177

Keefer ML, Caudill CC (2013) Homing and straying by anadromous salmonids: a review of mechanisms and rates. Rev Fish Biol Fisheries 24:333-368

Keesing JK, Lucas JS (1992) Field measurement of feeding and movement rates of the crown-of-thorns starfish Acanthaster planci (L.). J Exp Mar Bio Ecol 156:89-104

Kerkut GA (1953) The forces exerted by the tube feet of the starfish during locomotion. J Exp Biol 30:575-583

Kerkut GA (1954) The mechanisms of coordination of the starfish tube feet. Behaviour 6:206-232

Lamare M, Pecorino D, Hardy N, Liddy M, Byrne M, Uthicke S (2014) The thermal tolerance of crown-of-thorns (Acanthaster planci) embryos and bipinnaria larvae: implications for spatial and temporal variation in adult populations. Coral Reefs 33:207-219

Land MF, Nilsson D-E (2012) Animal eyes. Oxford University Press, Oxford
Lee C-C, Hsieh HJ, Hsieh C-H, Hwang D-F (2014) Spine venom of crown-of-thorns starfish (Acanthaster planci) induces antiproliferation and apoptosis of human melanoma cells (A375.S2). Toxicon 91:126-134

Lythgoe JN (1968) Visual pigments and visual range underwater. Vision Res 8:997-1012

Moore PA, Lepper DME (1997) Role of chemical signals in the orientation behavior of the sea star Asterias forbesi. Biol Bull 192:410-417

Mueller B, Bos AR, Graf G, Gumanao GS (2011) Size-specific locomotion rate and movement pattern of four common IndoPacific sea stars (Echinodermata; Asteroidea). Aquat Biol 12:157-164

Nilsson D-E (2013) Eye evolution and its functional basis. Vis Neurosci 30:5-20

O'Connor M, Nilsson DE, Garm A (2010a) Temporal properties of the lens eyes of the box jellyfish Tripedalia cystophora. J Comp Physiol A 196:213-220

O'Connor M, Garm A, Marshall JN, Hart NS, Ekström P, Skogh C, Nilsson D-E (2010b) Visual pigment in the lens eyes of the box jellyfish Chiropsella bronzie. Proc R Soc Lond B Biol Sci 277:1843-1848

Ormond RFG, Hanscomb NJ, Beach DH (1976) Food selection and learning in the crown-of-thorns starfish, Acanthaster planci $(\mathrm{L})$. Mar Behav Physiol 4:93-105

Osborne K, Dolman AM, Burgess SC, Johns KA (2011) Disturbance and the dynamics of coral cover on the Great Barrier Reef (1995-2009). PLoS ONE 6:e17516

Penn PE, Alexander CG (1980) Fine structure of the optic cushion in the asteroid Nepanthia belcheri. Mar Biol 58:251-256

Pratchett MS, Trapon M, Berumen ML, Chong-Seng K (2010) Recent disturbances augment community shifts in coral assemblages in Moorea, French Polynesia. Coral Reefs 30:183-193

Pratchett MS, Caballes CF, Rivera-Posada JA, Sweatman HPA (2014) Limits to understanding and managing outbreaks of crown-ofthorns starfish (Acanthaster spp.). Oceanogr Mar Biol Annu Rev $52: 133-200$

R Development Core Team (2012) R: a language and environment for statistical computing. Foundation for Statistical Computing, Vienna, Austria

Rivera-Posada J, Pratchett MS, Aguilar C, Grand A, Caballes CF (2014) Bile salts and the single-shot lethal injection method for killing crown-of-thorns sea stars (Acanthaster planci). Ocean Coast Manage 102:383-390

Romanes GJ (1883) Observations on the physiology of echinodermata. Zool J Linn Soc 17:131-137

Schalles J, Maeder J, Rundquist D, Narumalani S, Keck J (2000) Close range, hyperspectral reflectance measurement of coral and other reef substrates. Proc 9th Int Coral Reef Symp 2:1017-1024

Sheynikhovich D, Grèzes F, King J-R, Arleo A (2012) Exploratory behaviour depends on multisensory integration during spatial learning. In: Villa AEP, Duch W, Érdi P, Masulli F, Palm G (eds) Artificial neural networks and machine learning-ICANN 2012. Springer, Berlin, Heidelberg, pp 296-303

Sloan NA (1980) The arm curling and terminal tube-foot responses of the asteroid Crossaster papposus (L.). Journal of Natural History 14:469-482

Smith JE (1937) On the nervous system of the starfish Marthasterias glacialis (L.). Phil Trans R Soc Lond B Biol Sci 227:111-173

Spiess A-N, Neumeyer N (2010) An evaluation of $\mathrm{R}^{2}$ as an inadequate measure for nonlinear models in pharmacological and biochemical research: a Monte Carlo approach. BMC Pharmacol 10:6

Teruya T, Suenaga K, Koyama T, Nakano Y, Uemura D (2001) Arachidonic acid and $\alpha$-linolenic acid, feeding attractants for the 
crown-of-thorns sea star Acanthaster planci, from the sea urchin Toxopneustes pileolus. J Exp Mar Bio Ecol 266:123-134

Toyoda J-I, Coles JA (1975) Rod response to sinusoidally flickering light. Vision Res 15:981-983

Uthicke S, Logan M, Liddy M, Francis D, Hardy N, Lamare M (2015) Climate change as an unexpected co-factor promoting coral eating seastar (Acanthaster planci) outbreaks. Sci Rep 5:8402

Weissburg MJ, Zimmer-Faust RK (1993) Life and death in moving fluids: hydrodynamic effects on chemosensory-mediated predation. Ecology 74:1428-1443

Weissburg MJ, Zimmer-Faust RK (1994) Odor plumes and how blue crabs use them in finding prey. J Exp Biol 197:349-375

Wooldridge SA, Brodie JE (2015) Environmental triggers for primary outbreaks of crown-of-thorns starfish on the Great Barrier Reef, Australia. Mar Pollut Bull 101:805-815
Yerramilli D, Johnsen S (2010) Spatial vision in the purple sea urchin Strongylocentrotus purpuratus (Echinoidea). J Exp Biol 213:249-255

Yoshida M, Ohtsuki H (1966) Compound ocellus of a starfish: its function. Science 153:197-198

Yoshida M, Ohtsuki H (1968) The phototactic behavior of the starfish, Asterias amurensis Lütken. Biol Bull 134:516-532

Zann L, Brodie J, Berryman C, Naqasima M (1987) Recruitment, ecology, growth and behavior of juvenile Acanthaster planci (L.) (Echinodermata: Asteroidea). Bull Mar Sci 41:561-575

Zeil J, Nalbach G, Nalbach H-O (1986) Eyes, eye stalks and the visual world of semi-terrestrial crabs. J Comp Physiol A Neuroethol Sens Neural Behav Physiol 159:801-811 